\title{
The metabolic effects of limbic leucotomy in Gilles de la Tourette syndrome
}

\author{
G V Sawle, A J Lees, N F Hymas, D J Brooks, R S J Frackowiak
}

\begin{abstract}
Regional cerebral oxygen metabolism was measured before and after limbic leucotomy in a patient with Gilles de la Tourette syndrome, obsessive compulsive disorder, and obsessional slowness. The preoperative scan showed hypermetabolism in the caudate nuclei, which normalised after operation. It is proposed that the beneficial effects of this operation on both tics and obsessive compulsive behaviour are mediated by disruption of abnormal neural activity in basal ganglia-thalamocortical loops.
\end{abstract}

(F Neurol Neurosurg Psychiatry 1993;56:1016-1019)

Patients with the Gilles de la Tourette syndrome may also have obsessive compulsive disorder, and indeed genetic studies have suggested that these conditions, together with chronic tic disorder, might share a common hereditary basis. ${ }^{1} \mathrm{~A}$ further association with obsessive compulsive disorder is obsessional slowness, a condition where slowness dominates the clinical picture. ${ }^{2}$

Treatments for Gilles de la Tourette syndrome include behavioural therapy and dopamine blocking agents; clinical response to the latter implying an underlying dopamine receptor supersensitivity. ${ }^{3}$ Treatments for obsessive compulsive disorder include behavioural therapy, a variety of pharmacological agents, and various forms of frontal leucotomy; clinical response to the latter suggesting an overactivity in frontal cortex-basal ganglia connections. Positron emission tomography (PET) studies using tracers of energy metabolism in these conditions have shown hypermetabolism in the caudate nuclei and frontal cortex..$^{48}$ Studies of the dopaminergic system have been normal. ${ }^{9}$

\section{Case report}

A 45 year old man complained of compulsions to destroy things of value, to harm himself, to twitch and shout obscenities, and to hoard unnecessary objects. At the age of seven he had developed a tic of the head and neck associated with an indistinct vocalisation. At the age of 10 he had an urge to break windows, expose himself, burn money, or destroy his clothes, against his better judgment. When aged 35, he developed an urge to echo things he heard on television, in a crowd, or at the cinema. Daily activities were by now constantly interrupted by compulsions to harm himself, twitch or shout obscenities, leading to marked slowness in dressing, bathing, and eating. He took two hours to get out of bed in the morning after waking because of concern about which clothes he should put on and whether they were clean. His tendency to hoard objects led to his being charged with theft and losing his job as a laboratory technician. On psychiatric examination his mental state was dominated by obsessions and compulsions, but he was not clinically depressed and there were no psychotic features. On neurological examination he had facial tics and coprolalia. He had difficulty initiating movement but once started was able to execute movements fluently. There were no other neurological signs. An MRI scan was normal. Neuropsychological assessments revealed a Weschler Adult Intelligence Score (WAIS) verbal IQ of 108 and a performance IQ of 104 .

Although an intense programme of behavioural therapy initially led to a clear reduction in his obsessions and compulsions, follow up 2 months later showed a reversion to his former state. He was treated with a number of drugs including carbamazepine, chlorpromazine, clomipramine, clonazepam, fluvoxamine, haloperidol, pimozide, procyclidine, propranolol, and sulpiride, in each case without sustained benefit. Despite continued medical treatment he deteriorated further, becoming totally disabled by his tics and compulsions. Following approval by the Mental Health Commission he was referred to the Atkinson Morley's Neurosurgical Unit where he underwent bilateral limbic leucotomy in September 1989. Two pairs of lesions were produced by thermocoagulation, the first in the anterior hypothalamus and the second in the inferior part of the cingulate gyrus. Each lesion was approximately $1 \mathrm{~cm}$ in diameter. Postoperative neuropsychological assessments ( 1 month later) revealed a WAIS verbal IQ of 114 and a performance IQ of 97.

In the first 3 postoperative months he had a considerable reduction in his obsessions 

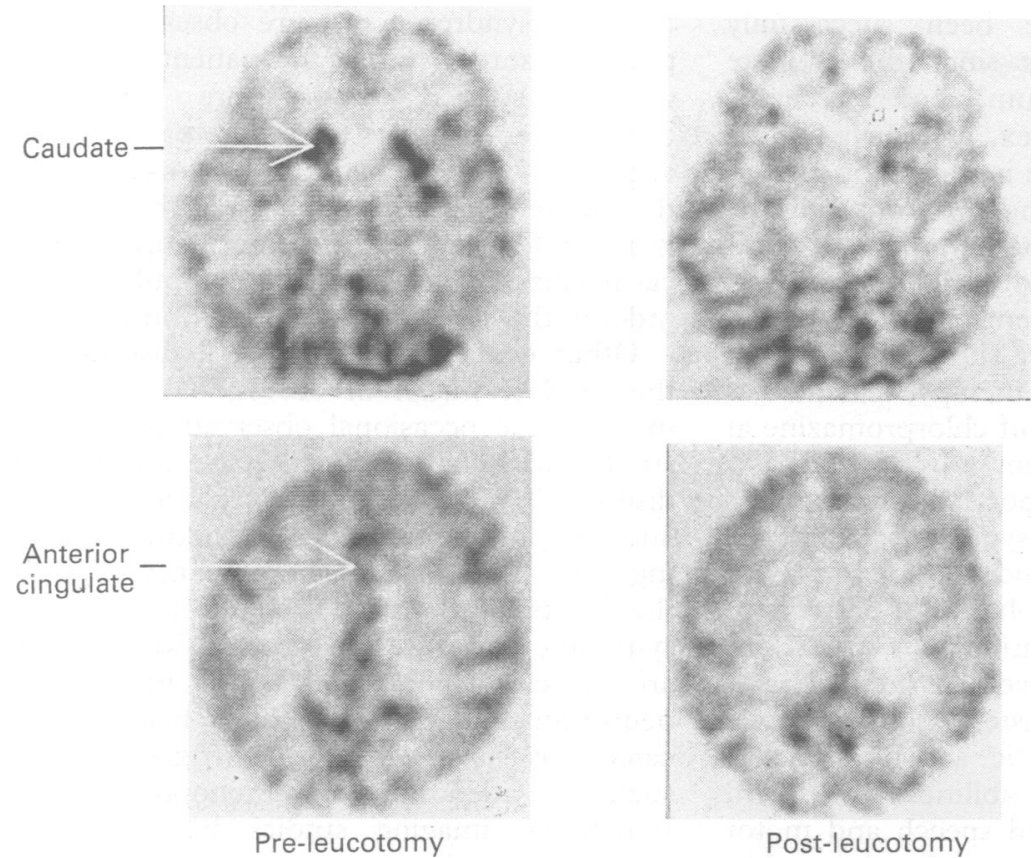

Figure Images of oxygen metabolism $\left(\mathrm{CMRO}_{2}\right)$. The upper left (preoperative) panel shows intense hypermetabolism in the caudate nuclei, normalised in the (postoperative) upper right panel. The lower images show reduced metabolism in the anterior cingulate in the postoperative scan (right) in comparison with the preoperative scan (left panel).

and by 6 months he subjectively reported an “overall $70 \%$ improvement". He was less inclined to tear his clothes but his tics, which were relatively mild preoperatively, were unchanged. By 1 year postoperation he reported a further improvement in his compulsions and by 14 months he had almost no signs of Tourette syndrome, though he was still troubled by urges to tear the buttons from his clothes. By 19 months he was living independently with no clinical signs of Tourette syndrome and he reported a substantial improvement in his obsessions.

Fifteen months before and 21 months after operation the patient underwent measurement of regional cerebral oxygen metabolism by PET using the steady state method ${ }^{1011}$ with ${ }^{15} \mathrm{O}_{2}, \mathrm{C}^{15} \mathrm{O}_{2}$, and $\mathrm{C}^{15} \mathrm{O}$ as tracers. Quantitative data were obtained by applying stereotactically positioned regions of interest to the image sets. ${ }^{11}$ The data were normalised to global metabolism and compared with data from six male age matched volunteers. All PET studies were performed under ethical approval and isotopes were administered with permission from the Administration of Radioactive Substances Advisory Committee of the United Kingdom (ARSAC). At the

Table Mean (of left and right) cerebral metabolic rate for oxygen consumption $\left(\mathrm{CMRO}_{2}\right)$ normalised to global metabolic rate

\begin{tabular}{llllr}
\hline $\begin{array}{l}\text { Anatomical } \\
\text { region }\end{array}$ & $\begin{array}{l}\text { Mean }(S D) \\
\text { CMRO } \\
\text { normal }(n=6)\end{array}$ & $\begin{array}{l}\text { Mean } \\
\text { CMRO } \\
\text { pre-op }\end{array}$ & $\begin{array}{l}\text { Mean } \\
\text { CMRO } \\
\text { post-op }\end{array}$ & $\begin{array}{l}\text { \% Change } \\
\text { CMRO } \\
\text { pre: post-op }\end{array}$ \\
\hline Caudate & $0.94(0.08)$ & 1.30 & 1.05 & -19.40 \\
Putamen & $1.06(0.12)$ & 1.19 & 1.24 & 4.70 \\
Anterior cingulate & $0.91(0.10)$ & 0.94 & 0.76 & -19.10 \\
Medial frontal cortex & $0.97(0.03)$ & 0.98 & 0.84 & -14.30 \\
Thalamus & $1.01(0.10)$ & 1.20 & 1.05 & -12.50 \\
Frontal lobe & $0.93(0.06)$ & 0.93 & 0.92 & -1.50 \\
Temporal lobe & $1.02(0.05)$ & 1.03 & 1.05 & 2.40 \\
Parietal & $1.01(0.03)$ & 1.05 & 1.10 & 5.50 \\
Occipital lobe & $1.04(0.04)$ & 1.10 & 1.12 & 1.60 \\
\hline
\end{tabular}

time of his initial PET study (June 1988) he was taking chlorpromazine $150 \mathrm{mg}$ daily and propranolol $40 \mathrm{mg}$ daily. At the time of surgery he was receiving chlorpromazine $100 \mathrm{mg}$ daily only. At the time of his second PET study (June 1991) he was taking chlorpromazine $150 \mathrm{mg}$ daily.

\section{Results}

The figure shows selected slices from preand postoperative images of oxygen metabolism. Representative slices from the level of the basal ganglia, and the anterior cingulate are shown for each study. The principal change demonstrated is a reduction in the rate of oxygen metabolism in these two structures.

Quantitative data for selected regions of interest are presented in the table. No other region showed such a marked reduction in metabolic rate following leucotomy; indeed many other regions showed a slight increase. Preoperatively the most striking hypermetabolism was measured in the caudate, although the thalamus was also hypermetabolic. The anterior cingulate, medial frontal cortex, and all whole lobe values were normal. Orbital frontal cortex values were not elevated. Postoperatively the greatest reductions in measured metabolic rate were in the caudate and the anterior cingulate, with lesser changes in the medial frontal cortex and thalamus. The only whole lobe value to show a fall was the frontal lobe.

\section{Discussion}

In considering the pathogenicity of both Gilles de la Tourette syndrome and obsessive compulsive disorder it is pertinent to consider the possibility of defects in the "lateral orbitofrontal" and "limbic" basal ganglia thalamocortical circuits respectively (for review see Alexander, et al ). ${ }^{12}$ The lateral orbitofrontal circuit comprises a loop from lateral orbitofrontal cortex via ventromedial caudate to rostromedial substantia nigra reticulata and dorsomedial globus pallidus interna, the latter structures projecting via medial thalamic nuclei back to the lateral orbitofrontal cortex. The limbic circuit is most easily visualised from the perspective of the ventral striatum which receives projections from the anterior cingulate and medial orbitofrontal cortex, as well as from many areas in the temporal lobe. It projects to the ventral pallidum which in turn projects via medial thalamus back to the anterior cingulate and medial orbitofrontal cortex. An aberrant loop to and from the orbitofrontal cortex involving the caudate nucleus, nucleus accumbens, globus pallidus, and dorsomedial nucleus of the thalamus has recently been proposed as a pathogenetic mechanism in obsessive compulsive disorders. ${ }^{13}$ The operation of limbic leucotomy selectively targets the anterior cingulate cortex and might therefore be expected to specifically influence the limbic basal ganglia thalamocortical circuit. 
This appears to have been successfully achieved in our patient since the caudate (including ventral striatum), anterior cingulate, medial frontal cortex, and thalamus all show a marked reduction in metabolic rate.

Other possible explanations for both the clinical change and metabolic change comprise either behavioural or pharmacological intervention. Neither seems likely, however, as the patient had never shown a sustained response to behavioural therapy, and he was receiving the same dose of chlorpromazine at the time of each PET scan.

Two other recent reports have described patients with Tourette syndrome submitted to the same operative procedure. One patient obtained a sustained resolution of destructive (particularly self-injurious) behaviour together with an improvement in his tics, ${ }^{14}$ another derived persistent but modest improvement in ritualistic activities, obsessions, and functional abilities. ${ }^{15} \mathrm{~A}$ third patient, who had delayed speech and motor development since early childhood in addition to the clinical diagnosis of Tourette syndrome, underwent bilateral cingulotomy twice. After the first operation he showed marked improvement for 10 days only. After repeat operation he showed moderate improvement in ritualistic behaviour. ${ }^{15}$ Larger patient numbers have been reported for the treatment of obsessive compulsive disorder using a similar operation, where more than $50 \%$ of patients have been reported to achieve a sustained marked improvement. ${ }^{16}$ Several patients with Tourette syndrome have been treated by coagulation of rostral intralaminar and medial thalamic nuclei. In three cases a marked improvement in the frequency of tics was reported, ${ }^{17}$ while in others the same operation failed to produce sustained benefit. ${ }^{18}$ In our patient the change in thalamic activity following cingulotomy was less marked than the changes in either the cingulate or caudate, nevertheless, it is possible that some of the improvement was directly related to changing neural activity in this structure.

In Gilles de la Tourette syndrome previous PET studies using $\left[{ }^{18} \mathrm{~F}\right]$ fluorodeoxyglucose have suggested glucose hypermetabolism in the basal ganglia, ${ }^{4}$ while in obsessive compulsive disorder the principal findings (persisting after normalisation to hemisphere values) have been in the frontal lobe..$^{5-8}$ We previously measured regional cerebral oxygen metabolism in a group of patients with obsessional slowness in the context of obsessive compulsive disorder (but none of whom had Tourette syndrome) and found hypermetabolism in the orbital frontal cortex, premotor cortex, and midfrontal cortex. ${ }^{11}$ Caudate values were normal. In this Tourette patient the most striking finding was of hypermetabolism in the caudate nuclei, while metabolic rates throughout the frontal cortex were normal. The inter-relationship between Tourette syndrome and obsessive compulsive disorder is complex, patients at either end of an apparently mixed spectrum showing either pure
Tourette syndrome or pure obsessive compulsive disorder. Since the patients we previously studied had pure obsessive compulsive disorder and this patient had additional Tourette syndrome, it may be that the different metabolic pattern in this patient is a manifestation of a different neurobiological mechanism for obsessive compulsive disorder in the context of Tourette syndrome.

Other evidence implicating a disorder of the caudate nuclei in obsessional disorders includes the occasional observation of focal striatal MRI changes in obsessive compulsive disorders ${ }^{19}$ and evidence of obsessive thoughts and compulsive behaviour in children suffering from Sydenham's chorea ${ }^{20}$; nevertheless the functional bases of Gilles de la Tourette syndrome and obsessive compulsive disorder are unclear. Abnormalities in a number of neurotransmitter systems have been implicated $^{21}$ as have second messenger systems such as adenosine 3'5'-monophosphate. ${ }^{22}$ Functional imaging studies have demonstrated metabolic changes in the cortex and basal ganglia, while abnormalities in the periaqueductal grey and midbrain tegmentum have been suggested by analogy with encephalitis lethargica and studies on the anatomy of vocalisation. ${ }^{23}$ In view of the striking male predominance in Tourette syndrome, a role for sex hormone influences mediated via excitatory neurotransmitter mechanisms has been suggested. ${ }^{24}$

This report underlines the significance of metabolic changes in the basal ganglia in Gilles de la Tourette syndrome, demonstrating a congruence between postoperative changes in metabolic activity and recorded clinical improvement.

1 Pauls DL, Leckman JF. The inheritance of Gilles de Tourette's syndrome and associated behaviors: evidence for autosomal dominant transmission. $N$ Engl f Med 1986;315:993-7.

2 Hymas NF, Lees AJ, Bolton D, Epps K, Head D. The neurology of obsessional slowness. Brain 1991;114: 2203-33.

3 Kurlan R. Tourette's syndrome: current concepts. Neurology 1989;39:1625-30.

4 Chase TN, Foster NL, Fedio P, et al. Gilles de la Tourette syndrome: studies with the fluorine-18labelled fluorodeoxyglucose positron emission tomography method. Ann Neurol 1984;15(suppl):S175.

5 Nordahl TE, Benkelfat C, Semple WE, Gross M, King AC, Cohen RM. Cerebral glucose metabolic rates in obsessive compulsive disorder. Neuropsychopharmacology 1989;2:23-8.

6 Swedo SE, Schapiro MB, Grady CL, et al. Cerebral glucose metabolic in childhood-onset obsessive-compulsive cose metabolic in childhood-onset obsessive-com
disorder. Arch Gen Psychiatry 1989;46:518-23.

7 Baxter LR, Phelps ME, Mazziotta JC, Guze BH, Schwartz JM, Selin CE. Local cerebral glucose metabolic rates in obsessive-compulsive disorder. Arch Gen Psychiatry 1987;44:211-8.

8 Baxter LR, Schwartz JM, Phelps ME, et al. Reduction of prefrontal cortex glucose metabolism common to three types of depression. Arch Gen Psychiat 1989;46:243-50.

9 Turjanski N, Lammeritsma AA, Sawle GV, Playford ED Lees AJ, Brooks DJ, PET studies of the dopaminergic system in Tourette's syndrome. Mov Disorders 1992; 7:51.

10 Frackowiak RSJ, Lenzi G-L, Jones T, Heather JD. Quantitative measurement of regional cerebral blood flow and oxygen metabolism in man using ${ }^{15} \mathrm{O}$ and positron emission tomography: theory, pro. $f$ Comput positron emission tomograph
Assist Tomogr 1980;4:727-36.

11 Sawle GV, Hymas NF, Lees AJ, Frackowiak RSJ. Obessional slowness: functional studies with positron Obessional slowness: functional studies with posit

12 Alexander GE, Crutcher MD, Delong MR. Basal gangliathalamocortical circuits: parallel substrates for motor, oculomotor, "prefrontal" and "limbic" functions. Prog Brain Res 1990;85:119-46. 
13 Modell JG, Mountz JM, Curtis GC, Greden JF. Neurophysiologic dysfunction in basal ganglia/limbic striatal and thalamocortical circuits as a pathogenetic mechanism of obsessive-compulsive disorder. 7 Neuropsychiatry 1989;1:27-36.

14 Robertson $M$, Doran M, Trimble M, Lees AJ. The treatment of Gilles de la Tourette syndrom by limbic leucotomy. $\mathcal{f}$ Neurol Neurosurg Psychiatry 1990;53:691-4.

15 Kurlan R, Kersun J, Ballantine HTJr, Caine ED. Neurosurgical treatment of severe obsessive-compulsive Neurosurgical treatment of severe obsessive-compulsive
disorder associated with Tourette's syndrome. Mov Disorders 1990;5:152-5.

16 Ballantine HT, Boukoms AJ, Thomas EK, Giriunas IE. Treatment of psychiatric illness by stereotactic cingulotomy. Biol Psychiatry 1987;22:807-9.

17 Hassler R, Dieckmann G. Traitement stereotaxique des tics et cris inarticules ou coprolalique cosideres comme phenomene d'obsession motrice au cours de la maladies de Gille de la Tourette. Rev Neurol 1970;123 89-106.

18 De Divitiis E, D'Errico A, Cerillo A. Stereotactic surgery in Gilles de la Tourette syndrome. Acta Neurochir 1977; 24:73.
19 Weilburg JB, Mesulam MM, Weintraub S, Buonanno F, Jenike $M$, Stakes JW. Focal striatal abnormalities in a patient with obsessive-compulsive disorder. Arch Neurol 1989;46:233-5.

20 Swedo SE, Rapoport JL, Cheslow DL, et al. High prevalence of obsessive-compulsive symptoms in patients with Sydenham's chorea. Am $\mathcal{f}$ Psychiatry 1989;146: 246-9.

21 Leckman JF, Riddle MA Cohen DJ. Pathobiology of Tourette's syndrome. In: Fredhoff AJ, Chase TN, et al, eds. Gilles de la Tourette syndrome. New York: John Wiley, 1988 : $103-16$

22 Singer HS, Hahn I-H, Krowiak E, Nelson E, Moran T. Tourette's syndrome: a neurochemical analysis of postmortem cortical brain tissue. Ann Neurol 1990; 27:443-6.

23 Devinsky O. Neuroanatomy of Gille de la Tourette's syndrome: possible midbrain involvement. Arch Neurol 1983;40:508-14

24 Kurlan R. The pathogenesis of Tourette's syndrome. A possible role for hormonal and excitatory neurotransmitter influences in brain development. Arch Neurol 1992;49:874-6. 